2 Thwaites $A$, Edmends $S$, Smith I. Inhalation induction with sevoflurane: a double-blind comparison with propofol. Br J Anaesth 1997; 78: 356-61.

3 Turino $M$, Kimura $H$. A comparison of vital capacity breath and tidal breathing techniques for induction of anaesthesia with high sevoflurane concentrations in nitrous oxide and oxygen. Anaesthesia 1995; 50: 308-11.

4 Yurino $M$, Kimura $H$. Vital capacity rapid inhalation induction technique: comparison of sevoflurane and halothane Can J Anaesth 1993; 40: 440-3.

\section{Cricoid pressure}

I read with interest the review article Cricoid Pressure by Brimacombe and Berry ${ }^{1}$ and I would like to make two points.

1. As regards regurgitation, it is important to realize that Oesophageal manometric measurements have shown that gastric reflex into the oesophagus occurs at a barrier pressure below $13 \mathrm{~cm} \mathrm{H}_{2} \mathrm{O}^{2}$. The barrier pressure is defined as the difference between the lower oesophageal sphincter pressure and gastric pressure, hence, barrier pressure is the physiological barrier to reflux. ${ }^{3}$ Therefore, if a patient with a basal barrier pressure of $26 \mathrm{cmH}_{2} \mathrm{O}$ is given a drug that decreases the lower oesophageal pressure by 14 $\mathrm{cmH}_{2} \mathrm{O}$, the lower oesophageal sphincter will be rendered incompetent. However, considerable individual variations in resting sphincter tone have been reported. ${ }^{4}$ It is obviously an advantage to increase the lower oesophageal pressure and, thereby, the barrier pressure by drugs like metoclopramide, domperidone, ranitidine, flunitrazepam. ${ }^{5}$ Even antacids can increase lower oesophageal sphincter tones.

2. As regards gastric insufflation, the authors refer to our article in Anesthesiology, ${ }^{7}$ but do not mention a very important finding in that paper. We studied 59 patients, from two weeks to eight years of age, who received routine general anaesthesia. In study \#l (without paralysis), the proximal airway pressure was slowly increased by gradually closing the pop-off valve on the anesthesia machine until gas was heard entering the stomach (pop-off point), or until the peak inspired pressure (PIP) reached $40 \mathrm{cmH}_{2} \mathrm{O}$. The same patients were then studied when paralyzed. The important finding was that in the paralyzed state, there was a considerably lower pop-off point than in the non-paralyzed state for any given patient. Cricoid pressure would seem even more important in paralyzed patients than previously realized.
I compliment the authors on the interesting review of cricoid pressure, however, I prefer to refer to cricoid pressure by the inventor, namely, Sellick manoeuvre. ${ }^{8}$

John G. Brock-Utne MD

Stanford, California, USA

\section{REFERENCES}

1 Brimacome JR, Berry AM. Cricoid pressure. Can J Anaesth 1997; 44: 414-25.

2 Haddad JK. Relation of gastroesophageal reflux to yield sphincter pressures. Gastroenterology 1970; 58: 175-84.

3 Brock-Utne JG, Ruben J, Downing JW, Dimopoulos GE, Moshal $M G$, Naicker $M$. The administration of metoclopramide with atropine. A drug interaction effect on the gastro-oesophageal sphincter in man. Anaesthesia 1976; 31: 1186-90.

4 Moossa $A R$, Skinner $D B$. Gastro-oesophageal reflux and hiatal hernia. A re-evaluation of current data and dogma. Ann R Coll Surg Eng 1976; 58: 126-32.

5 Brock-Utne JG, Downing JW. The lower oesophageal sphincter and the anaesthetist. S Afr Med J 1986; 70 : 170-1.

6 Beiles B, Picker $S$. The effect of intragastric aluminium hydroxide on lower oesophageal sphincter pressures. S Afr Med J 1972; 46: 1387-9.

7 Moyniban RJ, Brock-Utne JG, Archer JH, Feld LH, Kreitzman TR. The effect of cricoid pressure on preventing gastric insufflation in infants and children. Anesthesiology 1993; 78: 652-6.

8 Sellick $B A$. Cricoid pressure to prevent regurgitation of stomach contents during induction of anesthesia.

Lancet $1961 ; 2$ : 404-6.

\section{REPLY}

We thank Professor Brock-Utne for his interest in our review of cricoid pressure. We agree that the use of drugs to increase barrier pressure may play a role in protecting the patient from regurgitation and they should continue to be given. However, as we pointed out in the review, the impact of these drugs on patient outcome and the extent to which they are responsible for the reduction in maternal death from acid aspiration is unknown. We also agree that the risk of gastric insufflation may be higher in paralysed than nonparalysed patients and mention in the review that this important factor has not been adequately studied. Regarding use of the term "Sellick's manoeuvre," or "cricoid pressure," we actually prefer the latter since it better describes what occurs. In addition, some historical purists might insist on the term "Monro's" or "Hunter's" manoeupre.

J. Brimacombe, A. Berry

Cairns, Australia 